\title{
Erratum to: Complete affine connection in the causal boundary: static, spherically symmetric spacetimes
}

\author{
Steven (Stacey) G. Harris ${ }^{1}$
}

\section{Erratum to: Gen Relativ Gravit (2017) 49:31 DOI 10.1007/s10714-017-2187-x}

The original version of this article unfortunately contained a mistake. The name of the author was listed as Steven G. Harris instead of Steven (Stacey) G. Harris. The correct version is given here.

The original article was corrected.

The online version of the original article can be found under doi:10.1007/s10714-017-2187-x.

$\bowtie \quad$ Steven (Stacey) G. Harris

harrissg@slu.edu

1 Department of Mathematics and Statistics, Saint Louis University, St. Louis, MO 63103, USA 